\title{
ПРИРОДА ЧЕЛОВЕКА, ФЕНОМЕН АГРЕССИВНОСТИ И ВОЙНА (НЕКОТОРЫЕ ФИЛОСОФСКИЕ АСПЕКТЫ)
}

\section{HUMAN NATURE, THE PHENOMENON OF AGGRESSION AND WAR (SOME PHILOSOPHICAL ASPECTS)}

\section{S. Huseynova}

Summary:Wars, usually accompanying our history and bringing immense suffering, death and destruction to humanity, are one of the actual contemporary problems. A number of questions emerge in this regard. Why are we unable to prevent these wars? Why does our society, striving to be more humanistic, tolerate armed barbarism? Is the human mind helpless against this problem? How much does the reason and solution of the problem depend on the person himself? What are the prospects for solving the problem?

Trying to find answers to these questions, the article touches upon a number of philosophical aspects of the relationship of human nature, its phenomenon of aggressiveness with war, in which, although in a manner limited by rules, acts of aggression and violence are certainly used. The article first examines the attitudes of a number of scientists to human nature, the phenomenon of human aggression, as to the primary cause of war. In addition, the role of aggressiveness as an instrument of the goal of war or a means of obtaining pleasure, the possibility of reducing the intensity of aggression as a factor causing war, and its limitation in relation to military conflicts are discussed.

Keywords: human nature, aggressiveness, aggression, war, violence, humanistic society, catharsis, culture.

\author{
Гусейнова Севда Джумшуд кызы \\ Доктор философии по философии, дочент, \\ Азербайджанское Высшее Военное училище \\ имени Гейдара Алиева \\ adtesto@mail.ru
}

Аннотация: Войны, почти всегда сопровождавшие нашу историю и приносившие человечеству огромные страдания, смерть и разрушения, являются одной из самых острых проблем современности. В связи с этим возникает множество вопросов. Почему мы не в состоянии предотвращать эти войны? Почему наше общество, стремящееся быть более гуманистическим, терпит вооруженное варварство? Беспомощен ли человеческий разум перед этой проблемой? Насколько корень и решение проблемы зависят от самого человека? Каковы перспективы решения проблемы?

Чтобы попытаться найти ответы на эти вопросы, в статье затрагивается ряд философских аспектов взаимосвязи человеческой природы, его феномена агрессивности с войной, в которой, хотя и в ограниченном правилами порядке, но, безусловно, применяются акты агрессии и насилия. В статье, прежде всего, рассматривается отношение ряда ученых к человеческой природе, феномену человеческой агрессивности, как к первопричине войны. Также обсуждается роль агрессивности в качестве инструмента цели войны или средства получения удовольствия, возможность снижения интенсивности агрессии как фактора, вызывающего войну, и ее ограничение применительно к военным конфликтам.

Ключевые слова: природа человека, агрессивность, агрессия, война, насилие, гуманистическое общество, катарсис, культура.

войны, взаимосвязь между феноменом человеческой агрессивности и войной, а также заложена основа двух противоположных течений в вопросе роли человеческой природы в отношении войны.

В новую эпоху английский философ Томас Гоббс разработал теорию об агрессивной природе человека, заложившую основу для течения, приведшего в будущем к серьезным научным спорам по данному вопросу. Пытаясь объяснить природу человеческой агрессивности, Гоббс пишет, что в борьбе за достижение своей цели, которая состоит главным образом в сохранении жизни, а иногда в одном лишь наслаждении люди пытаются уничтожить или завоевывать друг друга. В человеческой природе Гоббс видит три причины конфликта: соперничество; недоверие; жажду славы [6]. Сторонник данного течения, австрийский ученый Зигмунд Фрейд, отмечая, что агрессивность людей является врожденной, пытается оправдать неизбежность войны. Разделяя человеческие влечения на эрос (защитные, объединяющие) и танатос 
(разрушительные, смертоносные), последние он называет агрессивными и деструктивными. Фрейд пишет, что оба эти влечения в равной мере необходимы, и инстинкт самосохранения, чтобы претвориться в жизнь, нуждается в агрессивности [11]. Другой австрийский ученый, Конрад Лоуренц в своей эволюционной теории также утверждает, что человеческая агрессия проистекает из инстинкта борьбы за выживание, но у человека способность ограничивать этот инстинкт слабее, чем у других живых существ. Он утверждает, что в результате развития науки и техники человек, приобретая оружие массового поражения, представляет еще большую опасность [9]. Наряду с Конрадом Лоуренцем и австралийским ученым Раймондом Дартом, другой эволюционист, американский писатель, ученый, археолог-любитель Роберт Ардри выдвинул интересную идею о том, что в основе человеческой агрессии стоит «природа охотника». Эти сторонники гипотезы «обезьян-убийц», основоположником которой является Раймонд Дарт, утверждают, что война и межличностная агрессия являются наследственной эволюционной чертой [13]. Французский ученый Норбер Рулан, опровергая эти представления, пишет, что охотник убивает без ненависти, чтобы добыть пропитание. Война же, требует агрессивности [4, стр.145]. Но, если мы просто обозрим историю человечества, увидим, что не все войны основаны на ненависти.

Американский научный публицист Джон Хорган выступает против идеи, что жестокие конфликты появились с первым человеком, и что последующие войны порождаются основными человеческими инстинктами господства или завоевания. Он утверждает, что тезис о том, что война - это не только агрессия или межличностное насилие, но и смертельный групповой конфликт глубоко укоренился в нашей эволюции и природе пропагандирован такими выдающимися учеными, как Джаред Даймонд, Ричард Рэнгхэм, Эдвард Уилсон и, прежде всего, психолог Стивен Пинкер. Обвиняя эту теорию в коварстве, отсутствии эмпирической поддержки, порождении пессимизма в обществе, он соглашается с автором «Истории войны» Джоном Киганом, что война по своей сути культурна, и причиной войны является не «человеческая природа» или конкуренция за ресурсы, а «сам институт войны» [14]. Подчеркивая необходимость уважительного отношения к его аргументам, надо обращать внимание на то, что отсутствие достаточного количества археологических артефактов не доказывает обнаружения истины. В науке, во многих случаях более поздно обнаруженные артефакты привели к полному опровержению предыдущих представлений. С другой стороны, если какая-либо научная концепция правдива, то она имеет право на существование, независимо от реакции, которую она вызовет в обществе, или от того, может ли она быть использована для других целей, включая политические. Самое главное, концепция глубоких корней войны не предполагает неизбежности войны. Каждый человек и человечество в целом сталкивается со многими отрицательными чертами, которые проистекают из его природы, и часто может отрицать их силой собственной воли. Чем больше человек сосредотачивается на своих внутренних инстинктах, рефлектирует, тем лучше он познает себя и учится лучше контролировать себя.

Джон Хорган обвиняет вышеупомянутых ученых в том, что они следуют тенденции Гоббса. Следует отметить, что Джон Хорган не единственный, кто не согласен с Гоббсом. Еще в эпоху Нового времени великий философ французского Просвещения Жан-Жак Руссо, в отличие от теории Гоббса об агрессивной природе человека как причине войны, считал, что человек в природном состоянии был свободен, мудр и сострадателен и при таком существовании войн не было. Цивилизация поработила, развратила и сделала человека неестественным. Само гражданское общество превратило человека в воинственное существо. [5, стр. 143]. Этот подход, положительно воспринимающий изначальную природу человека, получил множество сторонников в истории философской мысли. Например, русский философ Петр Кропоткин в труде «Взаимная помощь как фактор эволюции» пишет, что борьба в природе часто ограничивается межвидовой борьбой. Внутри одного вида и в большинстве случаев в группах, состоявших из различных видов, взаимопомощь является общим правилом [7]. В книге «Этика», написанной им в конце жизни, Петр Кропоткин пытается обосновать свои взгляды, отмечая, что инстинкт взаимопомощи, важный для существования, процветания и развития каждого вида, всегда был присущ человеку. Идентификация индивида с группой на самом деле основана на этом инстинкте. Склонность к конфликтам выгодна обществу только для разрушения несправедливых авторитарных режимов [8].

На фоне споров об агрессивной природе человека Джон Хорган считает более целесообразным принять классификацию по форме реактивной и проактивной агрессии вместо двух вышеуказанных направлений [14]. Как отмечают исследователи Р.Бэрон и Д.Ричардсон, агрессия может быть представлена в виде дихотомии (физическая - вербальная, активная - пассивная, враждебная и инструментальная и т. п.) $[2,31]$. Что касается деления на реактивную (защитную) и проактивную (неспровоцированное жестокое поведение), надо отметить, что предложенная Джоном Хорганом модель подробно изучается в трудах британского антрополога и приматолога Ричарда Врангама. Он пишет, что по сравнению с другими млекопитающими (напр. шимпанзе, бонобо) у людей чрезвычайно низкий уровень реактивной агрессии и чрезвычайно высокий уровень активной агрессии. По утверждению Ричарда Врангама, корни современной войны как раз находятся в разнице между 
«реактивной» и «активной агрессией» [15].

Существует и фрустрационная модель агрессивного поведения, в которой реактивная агрессия определяется как реакция защитного характера в ответ на реальную или ожидаемую угрозу, фрустрацию или провокацию. По этой теории (Джон Доллард, Нил Миллер, Леонард Дуб и др.), агрессия является результатом блокирования или фрустрирования усилий человека, направленных на достижение цели. Позже американский социальный психолог Леонард Берковиц подал идею, что отрицательный аффект и личные качества играют главную роль в провоцировании разочарованием агрессивного поведения [см.:12]. Французский философ, исследователь войны Раймонд Арон в своей книге пишет, что «физическая агрессия и воля к разрушению и уничтожению не являются единственной реакцией на фрустрацию, но они представляют собой одно из возможных реагирований и, наверное, как раз его спонтанную разновидность» [1, стр.409].

В целом определенная группа ученых выступает против объяснения проблемы только психологическими факторами. Теории же социального научения утверждают, что агрессия появляется только в соответствующих социальных условиях. Испанский философ XX века Хосе Ортега-и-Гассет в социально-философском трактате «Восстание масс» пишет: «нередко к насилию прибегают, исчерпав все средства в надежде образумить, отстоять то, что кажется справедливым». [3, стр.325].

Согласно рационалистической теории, во время войны обе стороны конфликта действуют разумно и исходят из желания получить выгоду. По Primat der Außenpolitik (Приоритет внешней политики) Карла фон Клаузевица и Леопольда фон Ранке, что война и мир являются следствием решений государственных деятелей и геополитической ситуации. Primat der Innenpolitik (Приоритет внутренней политики) Эккарта Kepa (Eckart Kehr) и Ханса-Ульриха Вэлера (Hans-Ulrich Wehler), считает, что война является продуктом местных условий, и внешними факторами определяется лишь направление агрессии.

Как видим, по интересующей нас проблеме существует множество теорий, многие из которых противоречат друг другу. Можно было обойти стороной эти теории, в которых отдельные положения можно оспорить, опровергнуть. Тем более, что многое из сказанного не подлежит верификации. Но все эти размышления носят в себе частицы истины и дают пищу для ума ученого, открывают стороны проблемы, которые надо изучить и анализировать, тем самым помогают найти подходы к изучаемой проблеме.

Как уже было сказано, война в классическом понимании этого слова всегда осуществляется посредством физического насилия. То есть, в войнах, ведущихся для любых целей - политических, экономических, религиозных и т.Д., акты агрессии неизбежны. Во время войны агрессивность в отношении вооруженных лиц или гражданского населения противника может проявляться в разных формах, интенсивности и масштабах. Даже в наше время, когда в мире широко распространены идеи более гуманистического подхода к войне, массовое и индивидуальное насилие в ходе боевых действий неизбежно. В этом случае агрессия и насилие, примененные во время войны, становятся инструментом достижения цели. Однако важно отметить, что в войне, ставшей инструментом реализации общественно значимых целей, желание причинить вред другому человеку или группе может проявляться независимо от основной цели войны. Оно также может проявляться в виде внутренних агрессивных тенденций, фрустраций и ответных реакций человека, столкнувшегося с агрессивным поведением во время боя. Гоббс писал, что человек вынужден принимать меры предосторожности, чтобы обезопасить свою жизнь, но некоторые продолжают захватывать их только для того, чтобы наслаждаться своей силой вовремя завоевании [6].

В наше время, с развитием науки и высоких цифровых технологий, в данном вопросе возникла противоречивая ситуация. С одной стороны, использование высокоточного оружия, растущие масштабы бесконтактных боев в современных войнах приводят к уменьшению этих агрессивных реакций, направленных на противника, а с другой стороны, вся агрессия сидящего перед монитором и уверенного в своей безопасности специалиста направлена на полное уничтожение сил противника, что во многом напоминает ему компьютерные игры. Поэтому получение наслаждения с помощью монитора при наблюдении за уничтожением врага может занять определенное место в духовной структуре некоторых военнослужащих.

У войны свои законы. Эти законы основаны на жизненных реалиях, а не на идеях. Как мы отметили выше, ответ на вопрос об источнике этих реалий часто остается открытым. Возникает ли агрессивность из желания достичь цели любой ценой или из темной для нас стороны человеческой природы является проблемой, создающей много вопросов для размышления, и которую достаточно сложно изучить с научной точки зрения. Террорист, убивающий ни в чем не повинных людей, даже женщин и детей, боевик, который совершает зверства «во имя религии», люди, уничтожившие, сжигавшие, удушавшие узников в концентрационных лагерях, которые не представляли военной угрозы... Что стоит за этими действиями? Поиск более легких способов достижения каких-то целей, искаженные религиозные взгляды или скрытые инстинкты, ищущие выход наружу? Те инстинкты, которые, подчиняя себе все чувства и мысли че- 
ловека, позволяют использовать насилие под разными предлогами для получения удовольствия, как бороться с такими состояниями, уничтожающими в людях лучшие человеческие качества?

Исследователи Р. Бэрон и Д. Ричардсон отмечают, что, если допустить проявление агрессивного поведения, как запрограммированного генетически, мы получим пессимистический вывод. Поскольку, в этом случае предотвратить проявления открытой агрессии невозможно. Можно их лишь временно сдерживать либо трансформировать в безопасные формы или направлять на менее уязвимые цели. Однако, если мы предположим, что агрессивное поведение явилось результатом научения, наш вывод будет более оптимистичным. Потому что в этом случае, изучая различные ситуационные, социальные и когнитивные факторы влияния, мы сможем предотвратить агрессивнее поведение [2, стр. 286,287].

Таким образом, мы видим два подхода к проблеме. Пессимистический подход полностью исключает возможность выхода из ситуации. В то же время, оптимистичный подход вселяет в нас твердую уверенность в том, что мы с помощью методов и инструментов, которые у нас есть или которых мы откроем в будущем, можем полностью достичь цели. На наш взгляд, на вопрос «возможно ли», вместо ответа «да» или «нет», было бы правильно ответить «надо стараться». Потому что ответ «нет» в любом случае ведет к поражению в «войне против войны», а решительное «да» создает иллюзию возможности предотвращения войн между людьми. Здесь основная задача - не переставая изучать эту проблему, решение которой мы возможно и не сможем найти в обозримом будущем, однако при этом необходимо искать более точные и доступные методы и средства воздействия на ход событий, возможность их практического применения. Необходимо проводить эксперименты в этой области, даже если это опасно, «пробовать и пробовать». Если теоретическая основа проблемы все еще неизученная, и в этой области мы не можем полностью полагаться на научную мысль, то эксперименты, проведенные с осторожностью, практическое применение новых идей, методов могут стать эффективными шагами в решении этой проблемы. В этом вопросе, главным образом, первично важно пытаться достичь желаемого результата за счет обеспечения совместной работы законов человеческой природы или их целенаправленного противопоставления друг другу, таким образом уменьшая или полностью предотвращая внутреннюю агрессию. По нашему мнению, важным инструментом в этом деле может стать принцип «противопоставление природы к природе». Это не самый простой способ вести борьбу против агрессивной воинственности, но его следует применить в первую очередь. При его удачном применении отпадет необходимость в гашении, сублимации, одним словом, нейтрализации агрессии, реализации методов социального воздействия, со свойственными им трудностями. Следовательно, в интересах человечества было бы найти всеобъемлющее, поэтапное решение проблемы. В качестве одного из способов ослабления агрессивности мы можем привести пример близкого к аристотелевскому пониманию, идею катарсиса, которая подразумевает очищение эмоций путем их переживания. Может казаться, что, при современном уровне информационных технологий, когда общество может воочию наблюдать за жертвами войн, очищение с помощью катарсиса не составит труда. Хотя влияния катарсиса, как может и правильно предполагал 3. Фрейд, кратковременны и малоэффективны, серия продолжающихся на разных частях мира вооруженных конфликтов не позволяет информационным экранам оставаться в стороне от угнетений войны или локального вооруженного конфликта. Создание эмпатии через информационные каналы может быть важным составным элементом в снижении агрессии через социальное воспитание.

Современные информационные технологии дают людям возможность лучше узнать друг друга и другие культуры. По словам канадского ученого Стивена Пинкера, в процессе эволюции, чем больше мы знаем о других людях и их культурах, тем выше поднимается у нас уровень эмпатии [10].

Однако обилие информации также может сыграть с людьми жестокую игру. Как показали Р. Бэрон и Д. Ричардсон, если агрессор очень раздражен или убежден в правоте своих действий, он может наслаждаться страданиями своих жертв [2, стр. 317]. Не исключено, что в этом случае, при виде страданий противника интенсивность воинственной агрессии у противоборствующих сторон возрастет. При данном положении прямое воздействие на сознание может сыграть важную роль как метод социального воспитания. Ознакомление противоборствующих сторон с культурой, позицией по вопросу конфликта друг с другом, привитие людям культуры прислушивания к противоположному мнению, убеждение их в необходимости искоренения насилия ради будущего человечества, могут стать факторами, снижающими интенсивность агрессивности.

Также существует теория высвобождения агрессии посредством «удаления лишнего пара», которая отражена в работах 3. Фрейда и его последователей. 3. Фрейд писал, что если готовность к войне является следствием деструктивной тенденции, проще всего направить эрос против нее [11]. В отличие от 3. Фрейда, К. Лоуренс считает, что предотвращение накопления агрессивной энергии каким-то образом возможно. Он предлагает два способа ограничения насилия. Первый - увести агрессию в другое русло. Второй - создать прочный союз, объединяющий двух или более «братьев» [9]. 
С другой стороны, вера в генетическое программирование агрессивного поведения также не должна быть основанием для пессимизма потому, что каждый человек индивидуально и социальные группы, общество в целом обладают способностью преодолевать свою собственную природу. Учитывая постоянную борьбу между добром и злом в духовном мире человека и его стремление контролировать свое поведение и даже мысли, мы можем надеяться, что отдельные люди, группы и человечество может ограничить эту генетическую программу в служении злу. Однако этот процесс требует большой воли и больших усилий.

Одним из инструментов ограничения актов агрессии, совершаемых во время войны, является наказание. Именно международное право, международные документы, заключенные между государствами, стали одним из факторов, ограничивающих агрессивное поведение в военное время, особенно совершавшихся против гражданского населения. Немедленное реагирование на военные преступления и распространение информации действует как своего рода предохранительный клапан. Однако в этом вопросе есть ряд нерешенных вопросов:

Во-первых, в современном мире существует ряд пробелов в предупреждении военных преступлений, в борьбе с ними, в наказании преступников. Это в основном связано как с определением преступления, так и механизмом наказания. Если человечество хочет двигаться к более гуманному обществу, оно должно постепенно увеличить как список наказаний, так и механизмы их исполнения. Несмотря на то, что с момента принятия ряда международных документов в этой сфере прошло много лет, проблемы с их реализацией все еще существуют. Возможно, из-за обновления самого человечества эти международные документы нуждаются в обновлении.

Во-вторых, неотвратимое наказание за военные преступления не гарантирует полного исключения таких случаев. Даже в странах с более совершенной судебной системой, существуют трудности с предотвращением преступлений. Это вдвойне сложно во время войны, когда из-за ненависти к врагу эмоции находятся в возбужденном состоянии, а поведение выходит из-под контроля.

В-третьих, боевики, которые иногда выступают сторонами в вооруженном конфликте, как правило, не осведомлены о международном праве или верят в свою безнаказанность. Это часто приводит к неограниченному поведению асоциальных людей, которые давно отошли от общественной жизни. В связи с этим не только военные, но и все другие слои населения должны быть информированы о сути военных преступлений.
Если не считать незаконные вооруженные формирования, именно государство формирует армию и основная ответственность преступлений военнослужащих ложится на государство. Это означает, что современное государство должно быть более внимательным при формировании своей армии - как в первоначальном подборе воинского контингента, так и в его последующем формировании в качестве военнослужащих. Что делать, если агрессивное поведение своих военных поощряются государством? Как наказать такое государство? Насколько виновны граждане государства, поощряющие агрессивное поведение своей армии? Как их наказывать? Это вопросы, на которые очень сложно, но необходимо найти ответы.

С другой стороны, в нашем современном мире армия выполняет очень важные функции и является бесценным инструментом государства, которое представляет важную форму организации современного общества. Армия часто используется государством для отражения агрессоров, борьбы с терроризмом, спасения жизней и защиты демократических ценностей и свобод. Эти действия, производимые армией, невозможны без актов агрессии, хотя и в ограниченном обществом объеме. В своем исследовании Стивен Пинкер приходит к заключению, что количество насилия в демократических обществах уменьшается [10]. Однако защита этого общества, даже если для этого нужно использовать насилие, также имеет первостепенное значение. То есть армия должна выполнять свою непростую защитную функцию в обществе. Выполнение армией своих функции возможно только с помощью актов агрессии. В связи с этим, полный отказ от агрессивности может помешать армии выполнять свои функции. Поэтому важно определить и содержать оптимальный уровень агрессивности в армии.

В современном обществе культура прививает нормы, определяющие допустимую форму и интенсивность агрессивного поведения в военное время. Однако у каждого человека есть определенная точка выбора в иерархии норм, разрешенных обществом или выходящих за рамки этого. Общество в целом и личность в отдельности, осознав природу агрессивного поведения через взаимное обогащение, в состоянии еще в большей степени ограничить его. Мнение общественности, сужая пределы агрессивности допустимые в условиях войны, может изменить отношение человечества к войне, способам ее ведения в будущем. Потому что, отделяя бесчеловечное от человеческого, мы еще больше очищаем нашу человеческую природу. Основная задача общества - помочь отдельному человеку осознать данный вопрос, а задача научных исследователей состоит в помощи обществу. 
ЛИТЕРАТУРА

1. Арон Р.Г. Мир и война между народами. M. Nota bene, 2000. -880с.

2. Бэрон Р., Ричардсон Д. Агрессия. СПб: Питер, 2001. -352 с.

3. Ортега и Гассет Х. Эстетика. М. Искусство, 1991. -588 с.

4. Рулан Н. Юридическая антропология. М. Норма, 1999. -301 с.

5. Руссо Ж. Ж. Об общественном договоре. Трактаты / Пер. с фр. М.: «КАНОН-пресс», «Кучково поле», 1998. -416 с.

6. Гоббс Т. Левиафан, или Материя, форма и власть государства церковного и гражданского URL: http://lib.ru/FILOSOF/GOBBS/leviafan.txt_with-big-pictures. $\mathrm{html}$

7. Кропоткин П. Взаимопомощь как фактор эволюции URL: https://theanarchistlibrary.org/library/petr-kropotkin-mutual-aid-a-factor-of-evolution

8. Кропоткин П. Этика: происхождение и развитие URL: https://theanarchistlibrary.org/library/petr-kropotkin-ethics-origin-and-development

9. Лоуренц К. Агрессия (так называемое «зло»). URL: http://lib.ru/PSIHO/LORENC/agressiya.txt

10. «Насилие нас зачаровывает»: нейропсихолог и писатель Стивен Пинкер о демократии в США и вреде анархии URL: https://www.forbes.ru/ forbeslife/413857-nasilie-nas-zacharovyvaet-neyropsiholog-i-pisatel-stiven-pinker-0-demokratii-v

11. «Неизбежна ли война?»: письмо Зигмунда Фрейда Альбрt Obama from Being a Peace President? URL: https://blogs.scientificamerican.com/cross-check/has-abogus-theory-of-war-kept-obama-from-being-a-peace-president/

12. Berkowitz L. Frustration-aggression hypothesis: Examination and reformulation. Psychol Bull 106:59-73, 1989.

13. Dart R.A. The Predatory Transition from Ape to Man // International Anthropological and Linguistic Review, v. 1, no.4,1953. URL: http://www.users.miamioh.edu/ erlichrd/350website/classrel/dart.html

14. Horgan J. Has a Bogus Theory of War Kept Obama from Being a Peace President. URL: https://blogs.scientificamerican.com/cross-check/has-a-bogus-theory-ofwar-kept-obama-from-being-a-peace-president/

15. Wrangham R. W. Two types of aggression in human evolution. URL: https://www.ncbi.nlm.nih.gov/pmc/articles/PMC5777045/

(с) Гусейнова Севда Джумшуд кызы (adtesto@mail.ru).

Журнал «Современная наука: актуальные проблемы теории и практики»

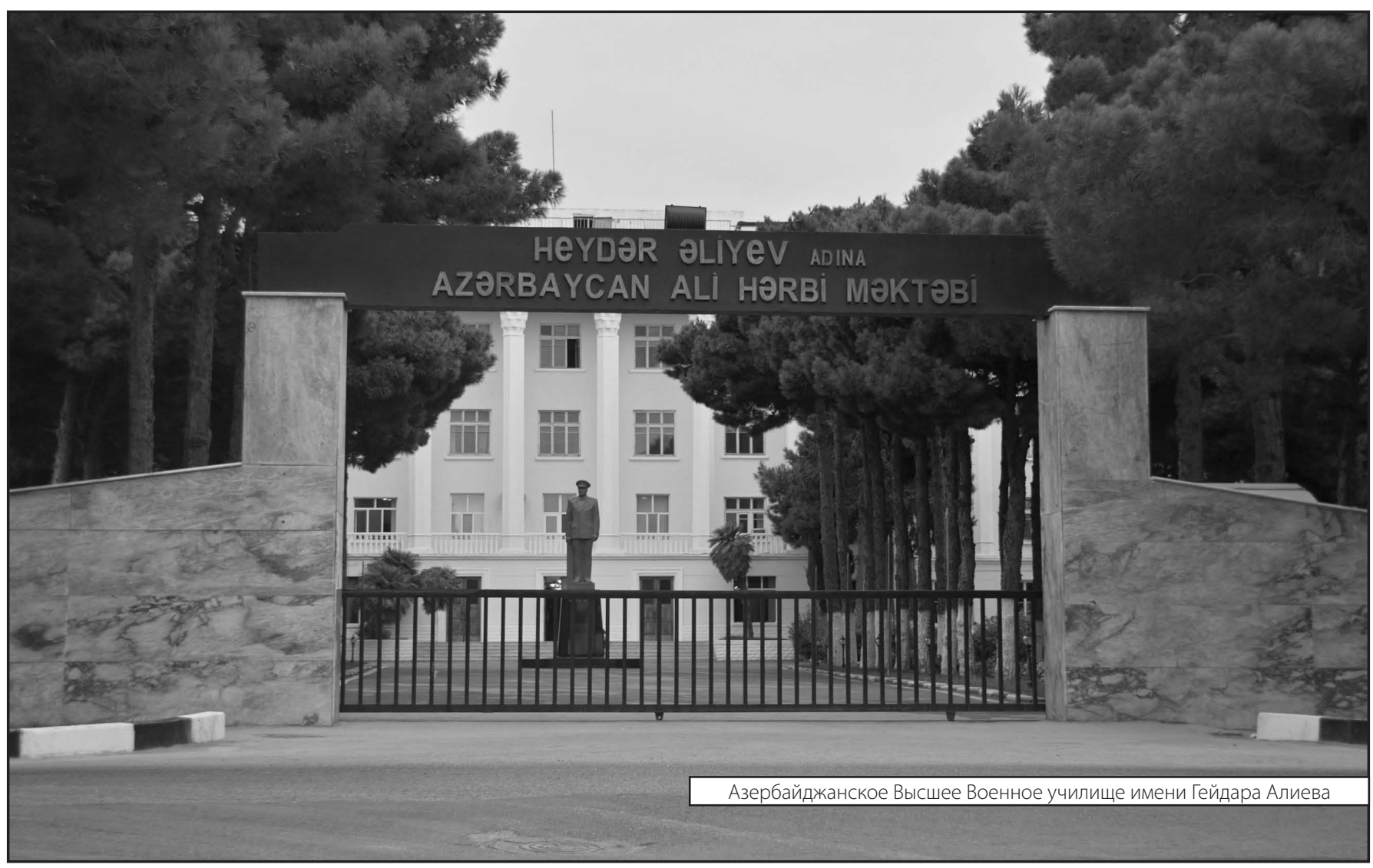

